\title{
Erratum to: Translating Molecular Biomarkers into Clinical Assays
}

\author{
Russell Weiner and Marian Kelley
}

\section{Erratum to:}

R. Weiner and M. Kelley (eds.), Translating Molecular

Biomarkers into Clinical Assays, AAPS Advances

in the Pharmaceutical Sciences Series 21, DOI 10.1007/978-3-319-40793-7

The book was inadvertently published with an incorrect volume number as 37 whereas the correct number for this volume is 21 . The erratum book has been Updated with the correction.

The original online version for this book can be found at 10.1007/978-3-319-40793-7

R. Weiner $(\bowtie)$

Translational Biomarkers and Personalized Medicine, Edison, NJ, USA

e-mail: usha.singh@merck.com

M. Kelley

MKelley Consulting LLC, West Chester, PA, USA

e-mail: mmk48@comcast.net 